\title{
El discurso politico de integración de los inmigrantes en el nivel regional en España: la division entre políticas de identidad y políticas sociales
}

Belén Fernández Suárez ${ }^{1}$

\section{Resumen}

Este artículo analiza el discurso de integración de inmigrantes en un nivel subestatal en tres Comunidades Autónomas en España: Cataluña, Madrid y Andalucía. Las políticas de integración de inmigrantes en España pueden ser definidas por un enfoque de gobernanza multinivel, donde la responsabilidad es compartida por el Estado, los gobiernos regionales y los municipios. Para analizar este discurso, los actores que se han tenido en cuenta son los representantes de los partidos políticos en los parlamentos autonómicos, los actores encargados de implementar estas políticas, al igual que los encargados de la toma de decisiones. La comparación de las tres Comunidades Autónomas nos permite testar la hipótesis de la convergencia en el discurso de integración al igual que los distintos debates que se producen a nivel regional, que son similares en una esfera global: quitar derechos sociales a los inmigrantes, discursos reactivos contra la inmigración y conflictos vinculados con la diversidad religiosa y cultural. Palabras clave: integración; políticas; inmigración; España; discurso.

${ }^{1}$ Universidade da Corunha, Galiza, Espanha. Facultade de Socioloxía, Universidade da Coruña, Campus de Elvinha, Elvinha, s/n., Profesora del Departamento de Sociología. Licenciada en Sociología. belen.fernandez.suarez@udc.es 


\section{0 discurso político de integração dos imigrantes em nível regional na Espanha: a divisão entre políticas de identidade e políticas social}

\section{Resumo}

Este artigo analisa o discurso de integração dos imigrantes em um nível subestatal em três regiões autônomas na Espanha: Catalunha, Madrid e Andaluzia. As políticas de integração dos imigrantes na Espanha podem ser definidas por uma abordagem de governabilidade em vários níveis, onde a responsabilidade é compartilhada pelo Estado, os governos regionais e municípios. Para analisar este discurso, os atores que foram tomados em consideração são os representantes dos partidos políticos nos parlamentos regionais, os atores responsáveis pela execução dessas políticas, bem como os tomadores de decisão. A comparação das três comunidades autônomas nos permite testar a hipótese de convergência no discurso de integração, bem como dos distintos debates que ocorrem a nível regional, que são semelhantes em uma esfera global: remover direitos sociais para imigrantes, discursos reativos contra a imigração e conflitos ligados à diversidade religiosa e cultural.

Palavras-chave: integração; políticas; Imigração; Espanha; discurso.

\section{La distinción como discurso en la integración de inmigran- tes: las palabras vuelan}

Politics takes place within language: within argument and rethoric which divide up, categorise and bound the social and cultural context of the policies, and which constrain and shape their development over time (Favell, 1998, p. 9).

Los actores políticos y sociales de un determinado territorio necesitan crear narrativas, y apoyar estas en discursos, para justi- 
ficar y legitimar sus políticas de integración al público (SCUZZARELLO, 2013, p. 1, 14). Las narrativas son elementos del proceso político que se caracterizan por su relativa coherencia, consistencia con la información disponible y que son comprensibles (BOSWELL, GEDDES AND SCHOLTEN, 2011, p. 2). El discurso político tiene una naturaleza más táctica, puede ser incoherente, y busca contentar a los distintos públicos (electorados). Podemos considerar la política del discurso como una política en sí misma, y que forma parte de las políticas de integración de inmigrantes (ZAPATA-BARRERO, 2013, p. 20-26). En la producción política de discursos influyen los distintos intereses en juego, lo que explica la ambigüedad, y la incoherencia de las propias políticas de integración de inmigrantes (BOSWELL, 2007, p. 79; CAIZA AND HAAS, 2013, p. 492). Este diferencial se ha denominado discursive gap y hace referencia a la discrepancia entre discursos públicos y políticas sobre el papel, como leyes y regulaciones. Esta diferencia se puede explicar por tres principales factores: a) las políticas de integración reciben la influencia de las intenciones y agenda de varios partidos políticos y grupos de interés, como el sector empresarial, sindicatos o la sociedad civil (FREEMAN, 2006, p. 33-40); b) determinadas circunstancias limitan las opciones políticas en democracias liberales; y c) los discursos migratorios son de largo alcance mientras que las prácticas políticas son específicas o dirigidas a algún grupo en concreto (MATHIAS AND HAAS, 2013, p. 494-496).

El estado, al igual que los gobiernos regionales, non son entidades monolíticas, y es necesaria una distinción entre el sistema de partidos políticos, que define una serie de creencias o valores al igual que los programas políticos, y la administración o el aparato burocrático que determina el contenido detallado y la implementación de las decisiones adaptadas, administración compuesta por diferencias agencias que persiguen metas y intereses diversos, y con variables grados de autonomía (BOSWELL, 2007, p. 79). La teoría neoinstitucional ha puesto el valor las resistencias al cambio que manifiestan las organizaciones burocráticas. 
En el terreno de las políticas de integración el discurso gana en importancia porque la presencia del "otro" hace que nos pensemos como comunidad, y supone un desafío al relato de un "nosotros" (FAVELL, 1998, p. 3-4, 24-25). Es en ese terreno donde la definición de la comunidad de pertenencia puede derivar en conceptualizaciones diversas, y más en el caso del Estado Español, donde las identidades de las regiones con lengua y cultura propias, denominadas por la Constitución "nacionalidades históricas", permite esa pluralidad de relatos comunitarios que enriquece la presencia de los "otros". Se trata pues de distinguirse del otro, de diferenciarse, en su visión de la identidad, pero también en el campo de las políticas públicas de integración de inmigrantes, y esta diferencia necesita de la "retórica" política y de diversos actores para su transmisión.

\section{M etodología: técnicas cualitativas para la compresión del discurso}

En este artículo se analiza el discurso sobre integración de inmigrantes en las comunidades autónomas de Cataluña, Madrid y Andalucía, que aglutinan el 52,4 por ciento del total de extranjeros empadronados en España (Padrón Municipal de Habitantes, Instituto Nacional de Estadística, 1 de Enero de 2014)².

Para ello expondremos las conclusiones del análisis de total de 98 entrevistas cualitativas realizadas en el ámbito autonómico

\footnotetext{
${ }^{2}$ Los datos provisionales del Padrón Municipal de Habitantes, a fecha 1 de Enero de 2014, señalan un importante descenso de la población extranjera residente en España a causa de emigraciones y consecución de la nacionalidad española, que alcanza la cifra de los 5 millones de extranjeros, que supone un peso del 10,7 por ciento de la población. Cataluña es la región con mayor número de personas extranjeras residiendo con un total de 1.085.976 (un 14,4 del total de la población es extranjera), seguida de la región de Madrid con 876.493 extranjeros (un 13,6 por ciento de la población total es extranjera), y en cuarta posición, después de la Comunidad Valenciana, tenemos a Andalucía con 657.815 extranjeros (7,8 por ciento de la población es extranjera). Link: www.ine.es [Último acceso: 30 de Febrero de 2015].
} 
y local, 59 y 39 entrevistas respectivamente, en estas regiones a los siguientes actores: partidos políticos, políticos responsables de la gestión, técnicos, sindicatos, entidades sin ánimo de lucro especializadas en temas de inmigración o con un área sobre migraciones, y finalmente, asociaciones de inmigrantes. En el caso de Cataluña se llevaron a cabo 27 entrevistas en el ámbito autonómico y 14 en el ámbito local ${ }^{3}$, lo que supone un total de 41 entrevistas en profundidad. En Madrid se realizaron 16 entrevistas en un nivel regional y 14 entrevistas en distintos municipios ${ }^{4}$ con fuerte presencia migratoria, lo que hace un cómputo global de 30 entrevistas. Finalmente, en Andalucía se llevaron a cabo un total de 25 entrevistas, 16 en el ámbito autonómico y 11 en el ámbito local $^{5}$. El trabajo de campo fue realizado entre el año 2009 y 2011, con lo que los análisis remiten a este período temporal.

Tabla 1: Cuadro tipológico de las entrevistas cualitativas realizadas en las Comunidades Autónomas de Cataluña, Madrid y Andalucía en el ámbito local y regional (2009-2011)

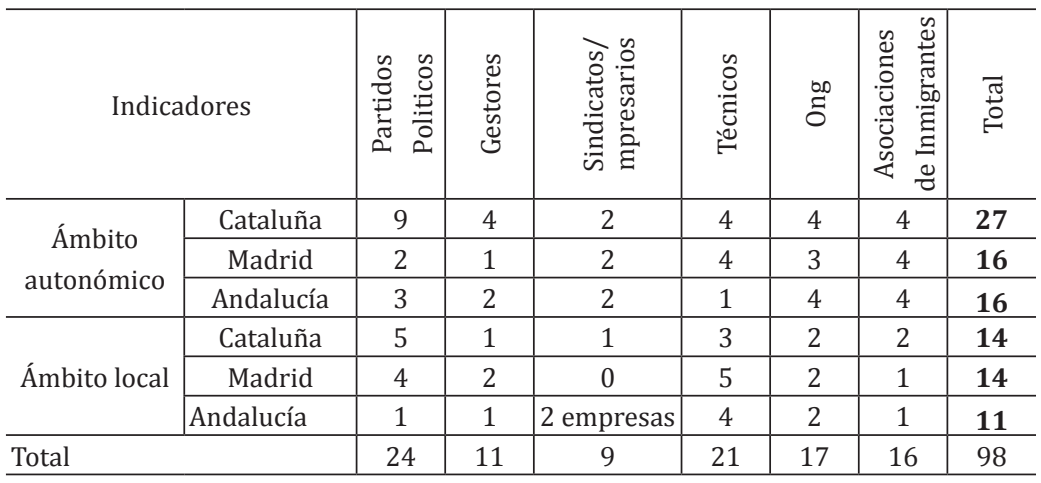

${ }^{3}$ Las ciudades catalanas en las que se realizaron entrevistas fueron Barcelona, Badalona (Barcelona), Olot (Girona), Vic (Barcelona), Mataró (Barcelona), Cervera (Lleida), Salt (Girona), Manresa (Barcelona), Girona y Tarragona.

${ }^{4}$ En la Comunidad de Madrid se realizó trabajo de campo en la ciudad de Madrid, en Alcalá de Henares, en Coslada, en San Fernando de Henares, en Getafe, en Móstoles, y en Fuenlabrada.

${ }^{5}$ En la Comunidad Andaluza las entrevistas realizadas tuvieron lugar en Sevilla capital, Roquetas de Mar (Almería), Cartaya (Huelva), Córdoba, Almería, y El Ejido (Almería). 
La relevancia que cobra el estudio del discurso autonómico y municipal radica en el hecho de que son las entidades subestatales quienes en gran medida implementan las políticas en el caso de España, lo que tiene un impacto sobre los discursos políticos sobre esta realidad, que a nuestro modo de ver se vuelven más pragmáticos, menos ideológicos y más sencillos en su argumentario, pues su público es más variopinto, con la excepción, de las grandes urbes, que como ciudades globales su gestión también se complejiza para políticos y gestores. Se trata, pues, de intentar visualizar este gap discursivo entre el ámbito regional y municipal en cuanto a su percepción de las políticas de integración de inmigrantes.

También este análisis se ha complementado con la revisión de legislación en materia de extranjería y la propia normativa creada en las distintas regiones con potestad para impulsar sus propias normas en su marco competencial, discursos realizados en sede parlamentaria que se recogen en los distintos diarios de sesiones, seguimiento de esta temática en los principales medios de comunicación y lectura de la producción de documentos de tipo institucional por los distintos gobiernos locales y regionales.

\section{La competencia en materia de integración de inmigrantes: el don de la ubicuidad}

¡Qué poco herméticas son las fronteras de los reinos humanos!/ ¡Cuantas nubes las cruzan sin castigo, /cuánta arena del desierto va de un país a otro, /cuántas arenas del desierto pasan de un país a otro, / cuántas piedras del monte ruedan en propiedad ajena/ saltando provocativas!" (...) Sólo lo humano sabe ser verdaderamente ajeno. / El resto son bosques mixtos, viejos topos y viento. (Wislawa Szymborska, Poema “Salmo", El gran número, Fin y principio y otros poemas. Edic. Hiparión, 1997).

El Estado, las administraciones regionales llamadas Comunidades Autónomas, y los municipios comparten de facto la autori- 
dad en materia de integración de inmigrantes en España. No han quedado bien definidas las competencias, aunque cada vez por la actuación del Tribunal Constitucional y por la propia práctica política se van definiendo con mayor precisión, aunque no están exentas de conflictos políticos.

La Constitución Española en su artículo 149.1.2. declara la exclusividad competencial del Estado en la gestión de la "nacionalidad, inmigración, emigración, extranjería, y derecho de asilo”. El artículo 148.1. de la Constitución Española establece que la asistencia social, salud, educación y cultura son responsabilidades de las Comunidades Autónomas. Por lo tanto, las normas más importantes en cada región denominados "Estatutos de Autonomía” han reclamado y recogido entre sus atribuciones estas y cada vez más áreas para descentralizar estas políticas públicas.

El Estado español es el responsable de la regulación la normativa de extranjería. Los Estatutos de Autonomía de Cataluña ${ }^{6}$

${ }^{6}$ El Estatuto de Autonomía de Cataluña (Ley Orgánica 6/2005 de 19 de Julio), aprobado en 2006 mediante consulta popular y ratificado con modificaciones por el Tribunal Constitucional, señala en su artículo 138.1. que son competencias de la Generalitat de Cataluña: "la primera acogida de personas inmigradas, que incluirá las actuaciones socio-sanitarias y de orientación”, el "desarrollo de política de integración de las personas inmigradas en el marco de sus competencias", "el establecimiento y la regulación de las medidas necesarias para la integración social y económica de las personas inmigradas y para su participación social", y el "establecimiento por ley de un marco de referencia para la acogida e integración de las personas inmigradas". A estas competencias hay que añadir la que aparece reflejada en el artículo 138.2 que afirma que le corresponde a la Generalitat la "competencia exclusiva en materia de autorización de trabajo de los extranjeros cuya relación laboral se desarrolle en Catalunya". El ejercicio de esta competencia se realizará en coordinación con el Estado que es responsable en materia de entrada y residencia de extranjeros. La Administración Autonómica se encargará de la "tramitación y resolución de autorizaciones iniciales de trabajo por cuenta propia o ajena", y hace referencia a los servicios portuarios y aeroportuarios que serán responsabilidad de la propia Generalitat previa negociación de su transferencia por parte del Estado. 
y Andalucía 7 , las normas más importantes en las distintas regiones, que desarrollan las competencias de las autonomías, y que forman parte de la normativa constitucional, se han apropiado de la gestión de los permisos iniciales de trabajo dejando para el Estado la gestión de los permisos de residencia, y han incluido entre sus competencias las políticas de integración de inmigrantes. Además, ambos territorios lograron, con el cambio de estatuto hace menos de una década, ganar mayor número de responsabilidades en material de inspección laboral. Lo cierto es que parte del Estatuto de Autonomía de Andalucía promulgado en 2007 copió los artículos de la norma catalana, la primera fue motivo de un recurso de anticonstitucionalidad ante el Tribunal, impulsada principalmente por el Partido Popular, el Defensor del Pueblo, y comunidades autónomas gobernadas en su mayoría por este partido, y por la contra, el Estatuto de Andalucía fue aprobado por consenso político de todas la fuerzas con presencia en su parlamento regional: Partido Popular, una fuerza de ideología conservadora y que defiende una visión nacionalista española; el Partido Socialista Obrero Español (PSOE), que podemos definir como un partido de gobierno socialdemócrata y que hace una defensa de una España federal; y, finalmente, Izquierda Unida, que es una federación de partidos que se define como socialista democrática

\footnotetext{
${ }^{7}$ La reforma del Estatuto de Autonomía de Andalucía (Ley Orgánica 2/2007 de 19 de Marzo), aprobado en el año 2007, recoge en el capítulo III, artículo 37.9. que uno de los principios rectores de las políticas públicas será "la integración laboral, económica, social y cultural de los inmigrantes". El artículo 62.1. del citado Estatuto de Autonomía asume que son competencias de la Comunidad Autónoma Andaluza las "políticas de integración y participación social, económica y cultural de los inmigrantes, en el marco de sus competencias". Además asume la "competencia exclusiva en materia de autorizaciones de trabajo de los extranjeros cuya relación laboral se desarrolle en Andalucía, en necesaria coordinación con la competencia estatal en materia de entrada y residencia, y de acuerdo con lo que establezca la legislación del Estado. Esta competencia incluye la tramitación y resolución de los recursos presentados a dichas autorizaciones y la aplicación del régimen de sanción e inspección". El artículo 62.2 de dicho Estatuto afirma que la Comunidad Autónoma participará en las decisiones del Estado sobre extranjería e inmigración que tengan especial trascendencia para esta autonomía, y más específicamente, en la fijación del contingente de trabajadores extranjeros.
} 
Montilla Martos y Rodríguez Candela (2011, p. 327-334) destacan que la sentencia del Tribunal Constitucional sobre el Estatuto de Cataluña abre la puerta para que todas las regiones puedan solicitar el traspaso de la competencia de la gestión de los permisos iniciales de trabajo, que por el momento sólo han recogido los estatutos catalán y andaluz, y sólo está ejerciendo dicha competencia la administración pública catalana.

Sin embargo, la ley que legisla las competencias políticas de los ayuntamientos, es decir, la Ley de bases reguladora del Régimen Local (Ley 7/1985), determina en su artículo 25.1. que el municipio "puede promover toda clase de actividades y prestar cuantos servicios públicos contribuyan a satisfacer las necesidades y aspiraciones de la comunidad vecinal". Es en este artículo 25 dónde se afirma de forma precisa que los municipios serán los encargados de la prestación de Servicios Sociales y de la promoción e inserción social.

¿Y finalmente quién es el responsable de las políticas de integración de extranjeros? En la práctica es una responsabilidad compartida entre todas las Administraciones Públicas. Su nacimiento y posterior desarrollo ha estado muy vinculada a los Departamentos de Bienestar Social autonómicos y en los Servicios Sociales de base municipales. Las competencias autonómicas, y particularmente las municipales, vinculadas a la integración de personas inmigrantes, no han sido recogidas de forma precisa en la legislación española (CAMÓS VICTORIA, 2007, p. 28-31).

¿Cómo se fue aclarando el mapa competencial en materia de integración de inmigrantes? Han sido las leyes de extranjería y sus reglamentos los que han otorgado en la práctica legitimidad a las distintas administraciones para actuar. Para comenzar, se han producido avances con la aprobación del reglamento ${ }^{8,}$ en el

${ }^{8}$ Real Decreto 2393/2004 de 30 de Diciembre que regula la Ley Orgánica 4/2000, de 11 de Enero, sobre derechos y libertades de los extranjeros. 
año 2004, que afirma que serán las autonomías las encargadas de certificar la adecuada integración social de los extranjeros en situación administrativa irregular. Los extranjeros en situación irregular que lleven residiendo en España 3 años, y cuenten con una oferta de trabajo, pueden regularizar su situación administrativa por la figura jurídica del denominado arraigo social ${ }^{9}$.

La ley de extranjería vigente en su artículo 2.ter afirma que los poderes públicos "promoverán la plena integración de los extranjeros en la sociedad española" y que las "Administraciones Públicas incorporarán el objetivo de la integración entre inmigrantes y sociedad receptora, con carácter transversal a todas las políticas y servicios públicos, promoviendo la participación económica, social, cultural y política”. Esta norma asevera que "la Administración General del Estado, las Comunidades Autónomas y los Ayuntamientos colaborarán y coordinarán sus acciones en este ámbito tomando como referencia sus respectivos planes de integración".

La actual ley orgánica de extranjería 2/2009 y su reglamento RD 447/2011 resaltan el papel de las Comunidades Autónomas en la gestión migratoria, o en caso de delegar, los municipios. Esta ley señala que serán las responsables de realizar el informe del esfuerzo de integración, necesario para que los inmigrantes puedan renovar sus autorizaciones de residencia temporal y laboral. Este esfuerzo, en la práctica, se concreta en la asistencia a cursos de formación, más concretamente, relacionados con conocimientos lingüísticos, culturales o legislativos de la sociedad de acogida.

La vigente ley, al igual que la anterior LO 4/2000 que sentó las bases normativas en los últimos años, delega en Comunidades Autónomas, y éstas a su vez pueden trasladar la responsabilidad

${ }^{9}$ La figura jurídica del "arraigo social" se mantiene en la vigente Ley Orgánica 2/2009, en su artículo 68.3. 
a los departamentos de Servicios Sociales de base de los distintos municipios, el informe sobre la adecuación de la vivienda que es necesario conseguir la tramitación del proceso de reagrupación familiar.

Esta corresponsabilidad entre administraciones públicas de la integración de inmigrantes se acentúa desde el año 2000 hasta la actualidad. A pesar la palpable complejidad en la gestión y coordinación del fenómeno migratorio en España, esta materia no provocó un excesivo conflicto competencial entre las Administraciones implicadas (MIRET I SERRA, 2009, p. 55-58).

¿Qué principios han guiado esta política de integración a nivel estatal? En líneas generales, a partir del año 2004, con la llegada al gobierno del Partido Socialista Obrero Español, se puede ver una influencia de la Comisión Europea y del Consejo de la Unión, que junto con los estados-miembros, aprobaron en el año 2004 una serie de "Principios Básicos Comunes sobre Integración"10, que destacan que para llevar a cabo una política de integración exitosa es necesario "comprometer a las instituciones locales, regionales y nacionales con las que interactúan los inmigrantes”.

Los principios básicos definen la integración como un proceso dinámico y bidireccional de ajuste mutuo por parte de todas las personas inmigrantes y los residentes de los estados-miembro de la Unión Europea. Estos principios ponen en el acento en cuestiones como una adecuada integración en el mercado de trabajo de los extranjeros, en la necesidad de conocer las lenguas y culturas de la sociedad de acogida por parte de la población extranjera, en la importancia de una adecuada integración y un progreso en el sistema educativo para garantizar la acomodación de los inmigrantes y sus descendientes, se hace una puesta por la igualdad en el acceso a bienes y servicios, se considera

${ }^{10}$ Consejo de Ministros de Justicia y Asuntos de Interior celebrado en Bruselas, el 19 de Noviembre de 2004. 
relevante fomentar una interacción frecuente y un diálogo intercultural entre extranjeros y autóctonos, se considera necesario apostar por la libertad religiosa y facilitar la práctica de las distintas religiones y culturas, se destaca la importancia de la participación de los extranjeros en el sistema democrático, destacan la importancia de que las políticas de integración sean integrales $\mathrm{y}$ transversales a todos los niveles de gobierno y, para finalizar, creen indispensable evaluar y medir el éxito o fracaso de estas políticas de integración de inmigrantes.

\section{Cataluña: ¿la globalización cerrará la fábrica de producción de catalanes?}

Cataluña es una comunidad autónoma con fuerte identidad política y cultural, que cuenta con una lengua propia y con instituciones históricas. Es también una zona que concentra una enorme riqueza en el último siglo derivada de su pujanza industrial. Al igual que España, puede definirse como un país de emigración durante el siglo XX, a la inversa, podemos afirmar que Cataluña cuenta con una larga tradición de tierra de acogida de inmigrantes, especialmente, migraciones interiores de españoles en dos oleadas históricas: 1919-1930 y 1951-1975, y de extranjeros, principalmente desde el año 2000 hasta el 2008, que se cierra un ciclo económico alcista, que necesitaba para su crecimiento económico de la llegada de trabajadores extranjeros para sectores productivos de mano de obra intensiva (construcción, servicios y hostelería).

Este hecho ha provocado la existencia de discurso histórico por parte de intelectuales, como de políticos, sobre la cuestión de la inmigración y la preocupación por la pérdida de identidad de Cataluña como nación sin estado. La filosofía de integración de Cataluña se ha basado históricamente en la metáfora de la "fábrica de catalanes", es decir, de conversión de los hijos de emigrantes en catalanes en un sentido pleno de pertenencia identi- 
taria. La fábrica ha funcionado razonablemente, a pesar de que en el año 1970 un 37 por ciento de la población catalana había nacido en el extranjero (DOMINGO, 2013, p. 12), porque ha logrado la movilidad social ascendente de parte de esta población. El discurso político hegemónico en la década de los sesenta, en parte acorde con los tiempos políticos y sociales que implicaba el final de la Dictadura Franquista, que hacía durado desde 1939 , recetaba la asimilación a la cultura catalana, aunque este modelo a la catalana entendía que había que tratar con respeto las tradiciónes culturales de sus lugares de preferencia. Pero aquí debemos señalar que la dictadura franquista prohibió, persiguió y reprimió cualquier expresión cultural y lingüística que no fuera el castellano, y eliminó cualquier libertad política en España, por lo tanto, Cataluña y el resto de autonomías no tenían posibilidades de gobernar y gestionar su territorio.

La duda que se nos presenta en tiempos de globalización económica es si la "fábrica de catalanes" podrá seguir su producción con mano de obra extranjera. Lo primero que hay que resaltar es el carácter profundamente democrático y cívico de la tradición política nacionalista catalana, y esto también tiene su traslado en el discurso en materia de integración de inmigrantes. Lo segundo que debemos resaltar es que el sistema político catalán es, sin lugar a dudas, el más plural y fragmentado de todos los parlamentos autonómicos existentes en España, al que sólo el caso vasco puede igualar, pensemos que en la legislatura actual (2012-2015) cuenta con la presencia de siete partidos políticos con sus respectivos discursos en esta materia. Y finalmente, destacar que el conflicto político identitario abierto entre Cataluña y España, con un desafío soberanista encima de la mesa, que es apoyado por una parte importante por de la sociedad catalana, también se ha trasladado al campo de la integración de inmigrantes principalmente en el tema de la integración cívica, y concretamente, con la cuestión de qué lengua, catalán o español, deben aprender en primer lugar los extranjeros residentes en Cataluña. 
El discurso político sobre integración de inmigrantes, por su tradición histórica, y también por contar con una inmigración menos similar tanto cultural como étnicamente a los autóctonos catalanes, como mayor presencia de población marroquí y asiática que en otras regiones del estado, junto con la preocupación por la identidad catalana hacen que el discurso migratorio tenga unas mayores dosis de pluralidad, complejidad y riqueza que en otras regiones estatales. Esto ha permitido que se pudieran dar los siguientes debates políticos en el parlamento y en la sociedad catalana a través de sus medios de comunicación: la posición sobre permitir el registro municipal de inmigrantes en situación administrativa irregulares en los distintos municipios, este trámite administrativo da acceso al uso y disfrute de recursos del Estado del Bienestar; el debate sobre el acceso a los derechos sociales y recursos del Estado del Bienestar, donde la cuestión estaba en garantizar este derecho para la población extranjera con permiso de residencia o mantenerlo para el conjunto de población migrante, a la par que se consideraba que el incremento de población no provocó una redimensión al alza de la inversión en políticas sociales; la ampliación de derechos políticos para la población extranjera, es decir, la concesión del sufragio en las elecciones locales y el cambio en la legislación de acceso a la nacionalidad española para flexibilizar la misma; el debate sobre la prohibición del burka en los espacios públicos; la visión sobre la integración de inmigrantes y su filosofía política; y finalmente, la inmigración y el uso de la lengua catalana.

Es imposible realizar una explicación pormenorizada de estos indicadores y discursos, pero quizás hay que dar una clave para entender los mismos, que consiste en que la mayoría de fuerzas políticas catalanas se define como catalanista, y esto ha provocado que este conjunto de partidos haya gobernado Cataluña desde la restauración de la democracia en 1978, y que existe una tradición de pacto entre las fuerzas políticas, en parte derivada del hecho de no contar con un estado propio para defender su cultura e identidad (nacional). Esto hace posible que esta zona 
sea el único territorio en contar con un Pacto Nacional por la Inmigración, y que fuese respaldado por las cuatro fuerzas con mayor respaldo parlamentario en el año 2008: Convergència i Unió [una fuerza nacionalista conservadora], Esquerra Republicana de Catalunya [un partido independentista, republicano y socialdemócrata], Partit dels Socialistes de Catalunya [es el Partido Socialista Obrero Español en Cataluña, se definen como catalanistas, federalistas y socialdemócratas], e Iniciativa per Catalunya e Esquerra Unida i Alternativa [son un partido de izquierdas, en la línea de las fuerzas verdes europeas, y con un importante sentimiento catalanista].

Dicho lo anterior, queremos destacar que la defensa de los derechos lingüísticos de los español-hablantes en Cataluña ha sido patrimonilizado por dos fuerzas políticas en esta comunidad: Partido Popular de Cataluña y Ciutadans-Partido de la Ciudadanía, que nace para realizar una defensa de la identidad española en Cataluña, pero que en la actualidad, está recogiendo parte del descontento popular por la incapacidad de los partidos tradicionales de resolver la crisis económica en España. Este es un tema que trasladado al campo de la inmigración provoca conflicto político porque los grupos catalanistas (independentistas, nacionalistas y federalistas) defienden que el inmigrante aprenda el catalán de forma preferente,y, en segundo término, el español si así lo desea. Los partidos que tienen un ideario de defensa de la nación española, con un discurso basado en la libertad de elección del individuo y contrario a las políticas de normalización lingüística del catalán, entienden que se deben ofertar cursos en las dos lenguas y dejarle escoger libremente al inmigrante.

Destacar que la demanda de requisitos cívicos en base a la integración es defendida por las fuerzas conservadores (españolas o catalanas) que son quienes mayor énfasis realizan en el discurso del miedo a la pérdida de identidad (sea cual sea), a lo que hay que sumar una exigencia de mayor esfuerzo de integración por parte de la comunidad inmigrante. Los partidos de centro- 
-izquierda, como es el caso del Partit dels Socialistes de Catalunya (PSC), tienen una posición intermedia porque aunque no protagoniza estas demandas, tampoco se posiciona de manera clara en su contra en aras de gobernabilidad. Son los partidos ecosocialistas y de una izquierda más radical quienes tienen posiciones contrarias a estas exigencias y más favorables al incremento de derechos sociales y políticos de los extranjeros.

La ley de la nacionalidad, en el caso español, favorece el acceso a los inmigrantes procedentes de territorios que fueron antiguas colonias españolas, y con afinidad tanto de tipo lingüístico como cultural, como es el caso de los inmigrantes latinoamericanos que pueden ser naturalizados después de dos años de residencia legal en España, en detrimento del resto de nacionales de países terceros que precisan de diez anos de residencia. La visión de la nacionalidad continúa ligada a un pasado emigratorio y colonial en España, esto sumado al hecho que no hubo incentivos ${ }^{11}$ para realizar la reforma de la ley en clave migratoria porque se ha buscado guardar un perfil político bajo en este tema, especialmente por fuerzas de centro-izquierda estatales, el caso concreto del Partido Socialista Obrero Español, y evitar la politización entorno a la inmigración (MARTÍN-PÉREZ Y MORENO-FUENTES, 2012, p. 626-627). Lo cierto es que la reforma de la ley de la nacionalidad fue apoyada por un número reducido de partidos políticos, como es el caso de Esquerra Republicana de Catalunya, Iniciativa per Catalunya y el Partido Socialista de Cataluña, que no logró el apoyo de su partido a nivel estatal con responsabilidades de gobierno hasta el año 2011, de esta propuesta se desmarcó el partido a nivel estatal por motivos que quedaron explicados con anterioridad.

\footnotetext{
${ }^{11}$ Martín-Pérez y Moreno-Fuentes destacan que la ley de nacionalidad es vista como bastante liberal por los políticos de las diversas ideologías, y que esto también tiene relación con el hecho de que existan pocas diferencias entre nacionales y extranjeros en términos de derechos y obligaciones, lo que hace que los incentivos se reduzcan para realizar un cambio aperturista que favorezca la flexibilización de la ley para el acceso a la nacionalidad de los extranjeros (MARTÍN-PÉREZ y MORENO-FUENTES, 2012, p.630-631, 641).
} 
En el tema del derecho al sufragio en las elecciones locales, la diferencia entre partidos se sitúa en el número de años necesarios de residencia, en España es necesario el reconocimiento del principio de reciprocidad electoral y la firma de un convenio para hacer efectivo el mismo, y el medio para poder ejercer el mismo desde el cambio constitucional hasta la firma de convenios con aquellos colectivos de inmigrantes con mayor presencia en el territorio. Los partidos de la izquierda alternativa o radical son más partidarios de menos requisitos y de realizar un cambio constitucional e, incluso, de expandir los derechos a otro tipo de elecciones, además de hacer de esta demanda una cuestión más propia de su discurso. Cuando más a la derecha menos proclives de la concesión de derechos políticos a la población extranjera.

Cataluña es el territorio donde mayor presencia ha conquistado en el ámbito local un partido anti-inmigración denominado Plataforma per Catalunya (PXC). Esta organización ha explotado en el ámbito local argumentos propios de los partidos de derecha radical populista europea, como la exigencia de que primeros son los nacionales, los extranjeros como consumidores voraces de recursos del Estado del Bienestar y atraídos a Cataluña por el welfare magnet (HERNÁNDEZ-CARR, 2013, p. 622; HERNÁNDEZ-CARR, 2011, p. 13-29), y el miedo al Islam reconvertido en islamofobia. En las localidades este discurso del miedo ha provocado concesiones simbólicas de los partidos de derechas tanto los nacionalistas catalanes, como los conservadores españoles, que pasan por crear un debate entorno a la posibilidad de no empadronar a inmigrantes irregulares, con la consiguiente marginación en el acceso al Estado del Bienestar, o la prohibición del burka que se convierte en un debate global (NUSSBAUM, 2013, p. 22; RAMÍREZ, 2011, p. 73-75). No obstante, ha sido la derecha nacional española quién más ha abanderado esta cuestión convirtiendo su discurso migratorio en más restrictivo en el acceso a derechos en Cataluña, en parte por sumar a su organización una nueva seña de identidad que pueda ser atractiva más allá de representar a la "marca" España en Cataluña. 
La visión del modelo de integración está caracterizado por el pragmatismo, y por los intentos de consensuar visiones entre clase política y representantes sociales, que pueden verse plasmados en el concepto "cultura pública común"12 de influencia que intenta ir más allá de la definición acuñada por el que fue presidente de la Generalitat Catalana casi más de veinte años, Jordi Pujol, que afirma que "catalán es todo aquel que vive y trabaja en Cataluña y que tiene voluntad de serlo". Este pacto lo que busca es una integración cívica basada en derechos y principios democráticos pero en una única sociedad catalana que sea reconocida como nación para la mayoría social de sus ciudadanos. Evidentemente, a determinados partidos cuya seña de identidad es el nacionalismo español esto les repele como mínimo denominador común.

Los sindicatos en Cataluña están integrados en una visión nacionalista catalana, lo cual ha facilitado los pactos y entendimientos con distintas fuerzas políticas catalanistas. Su discurso sobre la integración está centrado en el ámbito laboral, pero pueden permitirse una visión más crítica acerca del proceso de integración social y político donde suelen cargar las tintas de sus discursos. El tercer sector apuesta más por una integración social, de igualdad de oportunidades, como es de esperar por su profesionalización, y las asociaciones de inmigrantes, por sus caracterís-

${ }^{12}$ El Pacto Nacional por la Inmigración es un acuerdo firmado el 19 de Diciembre de 2008 entre distintas fuerzas políticas, sindicales y sociales de Cataluña que recoge la definición de "cultura pública común". Esta concepto se percibe como el "espacio compartido de comunicación, de convivencia, de reconocimiento y de participación de nuestra sociedad diversa y diferenciada, con el fin de que la nación catalana continúe siendo el referente de toda la población que en ella vive y trabaja" (artículo 145). En el Pacto se añade que las "bases de esta cultura pública común son los valores democráticos a los cuales aspiramos por tradición histórica, vinculada al respeto de los derechos humanos, y a la importancia concedida a la igualdad y el pluralismo como principios básicos de organización de la sociedad catalana. Pluralismo y diversidad que, en ningún caso, deben llevar a expresiones institucionales separadas o a una sociedad dividida por sus diferencias, en la que se establezcan relaciones de desigualdad entre formas de diversidad. Se entiende así que se debe reconocer cual forma de diversidad que respete los valores de convivencia democrática" (art. 146). Link: http://goo.gl/CJWkD2 [Último acceso: 3 de Marzo de 2015]. 
ticas, son más plurales, y nos encontramos con que las que se aglutinan entorno a colectivos que sufren más rechazo por parte de los nacionales, como sucede con las personas del Magreb, de Asia o de los países subsaharianos, tienen una visión más crítica con el discurso de integración que emana de los partidos políticos y más próxima a visiones multiculturales que implican una defensa de la cultura propia.

¿Hay gap discursivo en el ámbito local? En la política municipal se produce una paradoja curiosa, es más fácil el encuentro y el acuerdo entre organizaciones políticas que no podrían coincidir en el ámbito autonómico, y al vez, la llegada de Plataforma per Catalunya a los consistorios, los conflictos sufridos en algunas entidades que tienen relación con la gestión de la diversidad y la falta de recursos derivada de los recortes en todas las partidas sociales, como política de austeridad, han provocado un caldo de cultivo complicado de gestionar. En el ámbito del discurso podríamos decir que la identidad como sello de la integración a la catalana pierde peso en aras de un mayor pragmatismo en la acogida, y también destaca una visión más asimilacionista, en menor grado que en el resto de territorios estudiados, pero que también puede considerarse una tendencia generalizada. Desde lo local existe un cierto desapego al discurso en materia de inmigración realizado por sus respectivos partidos políticos desde el parlamento regional, consideran que falta realismo a su visión, y en ocasiones la desafección política se hace plausible, se sienten solos ante la gestión de la diversidad en sus respectivos municipios.

\section{La Comunidad de Madrid a la vanguardia de la producci- ón neoliberal en la visión de la inmigración}

Madrid es al igual que Barcelona una ciudad global, pero en este caso, tiene un efecto de centralidad que hace que en sus confines se concentren las principales instituciones estatales del poder ejecutivo, legislativo y judicial, al igual que el propio desarrollo 
de un gobierno regional, que tardó en ejercer competencias descentralizadas, pero que ha ganado mucho peso político en la última década y, finalmente, la propia capital de España se concentra también en esta región de pequeñas dimensiones. La centralidad no sólo provoca una concentración de instituciones, sino de recursos privados, no olvidemos que esta región ha sido de las que más han crecido económicamente en las últimas décadas en España.

Los gobiernos autonómicos han estado gobernado por mayorías absolutas del Partido Popular desde el año 1995, y será esta hegemonía política la que haya sido utilizada por este partido para utilizar el gobierno regional como un frente de oposición al gobierno socialista de Rodríguez Zapatero desde el año 2004 hasta el año 2011. Madrid ha sido el laboratorio de políticas neoliberales más importante del Estado Español, y a esto debemos sumarle la oposición visceral que desde esta comunidad se ha realizado contra los nacionalismos periféricos y sus reivindicaciones de mayores cuotas de autonomía.

El sistema político regional madrileño fue la mayor parte del tiempo tripartido en su composición, es decir, con la presencia del Partido Popular, Partido Socialista Obrero Español e Izquierda Unida. La cuestión de la identidad queda resuelta en un territorio que se identifica perfectamente con una única pertenencia, en este caso española, por lo tanto las diferencias se centran en las exigencias que se les imponen a los extranjeros para acceder a los derechos sociales y políticos durante su residencia en España.

El Partido Popular de Madrid, cómodo defendiendo posiciones liberales, es contrario a una reglamentación excesiva en cualquier tipo de política pública, pero defiende en el discurso que los extranjeros deben esforzarse para ganar su espacio en la sociedad de destino que se rige por un sistema meritocrático. El individuo debe ser libre para tener garantizada su autonomía, 
y que así sea capaz de responsabilizarse de sus acciones, entre ellas, lógicamente, deben asumir la decisión de integrarse en la sociedad de destino. Esta fuerza política que llegó a incorporar la defensa de la interculturalidad en su discurso, ha abandonado la misma, en aras de un discurso más ideológico basado en la defensa de los valores y legados de las sociedades occidentales e, incluso, de la herencia católica europea. La visión recentralizadora del Partido Popular madrileño ha llegado al extremo de solicitar la devolución de competencias en materia de extranjería al gobierno central, en clara oposición, a las demandas de mayores competencias procedentes de Cataluña y Andalucía.

El Partido Socialista de Madrid se define por la defensa de posiciones como la normalización en el acceso a los servicios públicos, la igualdad de oportunidades y la interculturalidad ${ }^{13}$. El discurso sobre integración cultural tampoco resulta relevante en una región como Madrid por dos cuestiones: los flujos asentados, en su gran mayoría latinoamericanos y rumanos, hacen entrever una proximidad cultural y lingüística que facilita su acomodación; y en segundo lugar, el eje político centro-periferia no existe en este territorio, por lo tanto, se intensifica las controversias entre igualdad y libertad. El Partido Socialista de Madrid ha visto como el Partido Popular se ha apoderado de un discurso socialdemócrata, que en parte no supo contrarrestar con la simple máxima de la igualdad de oportunidades.

${ }^{13}$ En el programa del Partido Socialista de Madrid (PSM-PSOE) de las elecciones autonómicas de 2011 se hacen un total de seis referencias a lo largo del texto a la palabra “inmigración”. Esta propuesta electoral contiene un apartado denominado "Integración e Interculturalidad" que incluye las propuestas en materia de integración de inmigrantes. En el mismo se defiende el principio de igualdad como aparece recogido en la siguiente frase: "Para los y las socialistas madrileños todas las personas que vivimos y convivimos en esta región, por el hecho de ser ciudadanos tenemos los mismos derechos y deberes. Nuestro trabajo se dirigirá a promover acciones que avancen en la efectiva igualdad de oportunidades y trato para una ciudadanía inclusiva desde una perspectiva integral y transversal y por estructuras ágiles y eficientes" (pág. 179). 
Izquierda Unida en la Comunidad de Madrid también defiende la igualdad real de oportunidades y derechos para los extranjeros, y se decanta por una defensa de servicios públicos universal por parte de todos los ciudadanos. Para que esto sea posible, es necesaria la redimensión del Estado del Bienestar en relación con la demanda de necesidades que han aumentado por el incremento poblacional. El matiz entre este partido de izquierdas y el Partido Socialista de centro-izquierda está en la gestión de los servicios públicos, Izquierda Unida defiende la titularidad y prestación de los servicios por parte de la Administración Pública, y el Partido Socialista no ve mal una externalización gestionada por el tercer sector. Esta organización defiende una integración ciudadana, denunciando en parte que en el debate público se ha producido una substitución de la lucha de clases por el choque cultural (MARTINIELLO, 1998). Defienden una integración intercultural, como una vía intermedia entre el asimilacionismo y el multiculturalismo, pero esta cuestión no es central en su discurso.

Los sindicatos en Madrid han sido fuertemente atacados por el gobierno regional y por el Partido Popular intentando relegar a los mismos a un segundo plano como agentes sociales cuyo papel está blindado por la Constitución Española como interlocutores en toda negociación colectiva vinculada a temas laborales. La visión de las organizaciones sindicales de clase es de defensa de la igualdad y de la unidad de la clase trabajadora, independientemente, de su procedencia. Su visión del extranjero es fundamentalmente como trabajador y, por lo tanto, su defensa radica de la igualdad en este sector de la sociedad. Debemos considerar que la afiliación de los trabajadores extranjeros a los extranjeros en todos los territorios está muy por encima de la media de trabajadores nacionales, viéndose más representados en las centrales sindicales que en otro tipo de organizaciones sociales.

La visión de la integración por parte del tercer sector es diversa, pero fundamentalmente orientada a un reconocimiento de de- 
rechos fundamentales, y terciada en parte por su trabajo directo con el colectivo de inmigrantes. El gobierno regional de Madrid consciente de que este sector, responsable en parte de la implementación de políticas específicas de integración, era próximo por su filosofía social a posiciones de defensa de la justicia social en lo político, decidió apostar por alimentar a un nuevo tejido social más afín en lo ideológico en dicha comunidad autónoma. Esto también influye en el discurso de las entidades con mayor solera en la intervención social, y intensifica la defensa de los servicios públicos en una región donde se había producido una fuerte externalización en la gestión e, incluso, privatización de terminadas prestaciones y servicios.

Finalmente, las asociaciones de inmigrantes fueron fuertemente apoyadas desde el Gobierno Regional, especialmente las de nuevo cuño, que eran más próximas en lo ideológico a posiciones ultrareligiosas. El discurso sobre la integración de la población extranjera es más crítico e, incluso, cuestionan este concepto por su corte funcionalista y siempre dependiente de la sociedad de acogida. En este terreno surge un discurso más cultural donde se defiende la interculturalidad como apuesta por lograr un respeto a las costumbres y riqueza de su comunidad por parte de la sociedad de acogida.

En el ámbito local no se produce una gran diferencia en relación con las posiciones de los partidos a nivel autonómico, pero si se rebaja el nivel retórico de las diferencias entre las distintas fuerzas y se aproximan los discursos en el ámbito de lo cultural, donde se defiende una asimilación de los extranjeros a la cultura de la sociedad de acogida. No obstante, la tradición municipalista de Madrid siempre se ha caracterizado por contar con fuertes dispositivos de Servicios Sociales y apostar por una igualdad en el acceso a los servicios públicos de todos los ciudadanos. 
Andalucía como puerta de entrada de la inmigración y su apuesta por la integración social

Andalucía es la región con mayor número de residentes y la que cuenta con una mayor extensión territorial. Se trata de una región declarada nacionalidad histórica, junto con Cataluña, País Vasco y Galicia, lo que supuso que su Estatuto de Autonomía recogiese de entrada un mayor número de competencias y un desarrollo más temprano de su autogobierno. No obstante, a pesar de una defensa de su identidad y de los derechos políticos, que esta comportaba al comienzo de la transición democrática en España, los andaluces que ven su región como una nación sin estado son minoría, al igual que muy escaso el apoyo a fuerzas políticas que promulgan un ideario político nacionalista para Andalucía.

Esta realidad política hace que en su parlamento regional tengan representación tres fuerzas políticas, al igual que en el caso madrileño, son el Partido Popular, el Partido Socialista Obrero Español e Izquierda Unida. Esta región ha sido gobernada desde la transición democrática en España por el Partido Socialista Obrero Español, lo que es un indicador sociológico, del fuerte peso y defensa que realizan los ciudadanos de valores como la igualdad, el reparto de la riqueza y la solidaridad entre personas. También en cuanto a la llegada de inmigrantes podríamos decir que destaca la necesidad de mano de obra en sectores puerta de entrada como la agricultura en Almería y Huelva, y en el sector de la hostelería en toda la costa por el fuerte peso del sector turístico, y en el sector servicios principalmente en las grandes urbes.

La cuestión de la integración de inmigrantes no genera grandes discrepancias en el discurso político, al contrario de lo que sucede en Cataluña, con una gran producción de debates en sede parlamentaria, en medios de comunicación y en la sociedad en su conjunto. El Partido Socialista Obrero Español hace de la 
igualdad su bandera en esta cuestión y, en este caso, su principal preocupación está relacionada con las condiciones de vida de los inmigrantes irregulares en los campos de la agricultura. La propia apuesta de abordar la integración desde el ámbito social, y buscar la normalización en el acceso a los servicios, apunta en líneas generales en dicha dirección.

Para el Partido Popular, principal aspirante a gobernar la comunidad, pero siempre en la oposición, el tema de la inmigración no juega un papel central en su discurso. En todo caso, se busca desgastar al gobierno regional con temas vinculados con la necesidad de articular una migración ordenada y poner fin a la llegada de inmigrantes en situación irregular. No hay un discurso alternativo en esta cuestión, sólo el acento se coloca en la necesidad de que los extranjeros deben no sólo disfrutar de derechos sino ejercer sus deberes con el resto de ciudadanía.

Izquierda Unida en la comunidad andaluza tiene un discurso muy obrerista que pivota en la unidad de la clase trabajadora. Los inmigrantes son vistos como mano de obra y, por lo tanto, se hace una defensa de sus derechos como trabajadores acusando a los empresarios de las situaciones de explotación que pueden sufrir los extranjeros.

Los sindicatos en este territorio tienen mayor discurso sobre control de fronteras y contingentes de trabajadores extranjeros, que sobre individuos residentes que tienen un proyecto migratorio de asentamiento. Las entidades del tercer sector, claramente las responsables de la implementación de políticas de integración junto con los ayuntamientos, son proclives tanto al discurso de la interculturalidad, como a la defensa de la igualdad real. Sin embargo, son las asociaciones de inmigrantes las que realizan una mayor defensa de posiciones interculturales, de lucha contra actitudes racistas y, finalmente, una visión defensiva ante el proceso de acogida en la sociedad andaluza. 
En el ámbito local el discurso sobre la integración es abiertamente asimilacionista sin excesivos matices, y en relación con la igualdad de oportunidades se produce una defensa desde una visión paternalista de los inmigrantes residentes en esta región.

\section{Conclusiones: el federalismo asimétrico español también genera gaps en las políticas de integración de inmigrantes}

El diverso desarrollo de los gobiernos regionales y la existencia de posiciones de defensa de una identidad propia como reivindicación marcan en gran medida la creación de discurso en las distintas áreas sociales y, en este sentido, la integración de inmigrantes como política pública no es una excepción.

Es Cataluña sin duda quién lidera la producción política discursiva, con sus ricos matices y diferencias, en relación con otras regiones españolas en cuanto a su visión más allá del eje entre igualdad y libertad presente en el marco madrileño y andaluz.

En los tres territorios, eso sí, se forjan discursos de consenso acerca de una determinada visión del nosotros que pasan por ser Cataluña una país de inmigración y que este rasgo forma parte de su identidad, hasta el caso de Madrid, que se va a si misma como tierra de acogida y abierta a la llegada de nuevos residentes, hasta la propia comunidad andaluza que se percibe como tierra de emigración y, por lo tanto, la solidaridad forma parte de su sello de identidad. 
Tabla 2. Comparativa del discurso de los partidos políticos con representación parlamentar en las autonomías de Madrid, Andalucía y Cataluña (2006-2010)

\begin{tabular}{|c|c|c|c|}
\hline \multirow{4}{*}{ 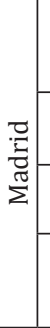 } & $\begin{array}{l}\text { Partidos } \\
\text { Políticos }\end{array}$ & \begin{tabular}{|c|} 
Elecciones \\
Autonómicas \\
2007 \\
\end{tabular} & Visión de la integración \\
\hline & $\begin{array}{l}\text { Partido } \\
\text { Popular }\end{array}$ & \begin{tabular}{|c|}
67 escaños \\
$(53,3 \%$ voto $)$ \\
\end{tabular} & $\begin{array}{l}\text { Integración por vía contractual. Derechos condicionados } \\
\text { a deberes. Integración cívica (y cultural). }\end{array}$ \\
\hline & PSM-PSOE & $\begin{array}{c}42 \text { escaños } \\
(33,5 \% \text { voto })\end{array}$ & $\begin{array}{l}\text { Normalización en el acceso a los servicios públicos. } \\
\text { Igualdad de oportunidades. Interculturalidad. }\end{array}$ \\
\hline & $\begin{array}{l}\text { Izquierda } \\
\text { Unida }\end{array}$ & $\begin{array}{l}11 \text { escaños } \\
(8,9 \% \text { voto })\end{array}$ & $\begin{array}{l}\text { Integración ciudadana. Igualdad social e inclusión polí- } \\
\text { tica de los inmigrantes. Normalización y servicios públi- } \\
\text { cos para el conjunto de ciudadanos. }\end{array}$ \\
\hline \multirow{4}{*}{$\begin{array}{l}\frac{\pi}{0} \\
\frac{\pi}{3} \\
\frac{\pi}{2} \\
\frac{\pi}{4}\end{array}$} & $\begin{array}{l}\text { Partidos } \\
\text { Políticos }\end{array}$ & \begin{tabular}{|c|} 
Elecciones \\
Autonómicas \\
2008 \\
\end{tabular} & Visión de la integración \\
\hline & PSOE-A & $\begin{array}{c}56 \text { escaños } \\
(48,4 \% \text { voto })\end{array}$ & $\begin{array}{l}\text { Peso en el discurso del pasado emigratorio de la región. } \\
\text { Integración social de los inmigrantes. Igualdad de trato } \\
\text { y crítica al contrato de integración. }\end{array}$ \\
\hline & $\begin{array}{l}\text { Partido } \\
\text { Popular }\end{array}$ & $\begin{array}{c}47 \text { escaños } \\
(38,6 \% \text { voto })\end{array}$ & $\begin{array}{l}\text { Graduación de la ciudadanía social en relación con vin- } \\
\text { culación laboral/esfuerzo de integración. }\end{array}$ \\
\hline & $\begin{array}{c}\text { Izquierda } \\
\text { Unida }\end{array}$ & $\begin{array}{l}6 \text { escaños } \\
\text { (7\% voto) }\end{array}$ & $\begin{array}{l}\text { Defensa de derechos laborales, sociales y políticos de los } \\
\text { extranjeros. Igualdad de derechos. }\end{array}$ \\
\hline \multirow{7}{*}{ 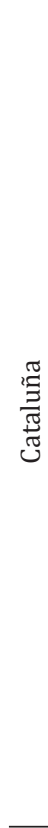 } & $\begin{array}{l}\text { Partidos } \\
\text { Políticos }\end{array}$ & \begin{tabular}{|c|} 
Elecciones \\
Autonómicas \\
2006 \\
\end{tabular} & Visión de la integración \\
\hline & $\mathrm{CiU}$ & $\begin{array}{l}48 \text { escaños } \\
(32,2 \% \\
\text { voto })\end{array}$ & $\begin{array}{l}\text { Esfuerzo de integración, los derechos deben traer obli- } \\
\text { gaciones. Asimilacionismo en el proyecto de construc- } \\
\text { ción nacional catalán. Aceptación limitada de amplia- } \\
\text { ción de derechos políticos. }\end{array}$ \\
\hline & PSC & $\begin{array}{c}37 \text { escaños } \\
(27,4 \% \text { voto })\end{array}$ & $\begin{array}{l}\text { Igualitarismo, pero con acercamiento a la idea de esfuer- } \\
\text { zo de integración (posición de gobierno). Apuesta por la } \\
\text { acomodación. Visión colectiva de la integración (influen- } \\
\text { cia de la emigración interior). }\end{array}$ \\
\hline & ERC & $\begin{array}{c}21 \text { escaños } \\
(16,6 \% \text { voto })\end{array}$ & $\begin{array}{l}\text { Igualitarismo republicano catalán. Asimilación en el } \\
\text { proyecto de construcción nacional catalán. Aceptación } \\
\text { de ampliación de derechos políticos. }\end{array}$ \\
\hline & $\begin{array}{l}\text { Partido } \\
\text { Popular de } \\
\text { Cataluña }\end{array}$ & $\begin{array}{c}14 \text { escaños } \\
(10,9 \% \text { voto })\end{array}$ & $\begin{array}{l}\text { Esfuerzo de integración, derechos a cambio de deberes. } \\
\text { Asimilacionismo en la cultura española. Reacio a la am- } \\
\text { pliación de derechos políticos más allá de la normativa } \\
\text { vigente. Individuo debe ser autónomo, críticos con la } \\
\text { cultura de la dependencia. }\end{array}$ \\
\hline & ICV-EUiA & $\begin{array}{l}12 \text { escaños } \\
(9,7 \% \text { voto })\end{array}$ & $\begin{array}{l}\text { Interculturalidad. Defensa de la extensión de derechos } \\
\text { políticos. Normalización y igualdad en el acceso al Esta- } \\
\text { do del Bienestar. }\end{array}$ \\
\hline & Ciutadans & $\begin{array}{c}3 \text { escaños } \\
(3,1 \% \text { voto })\end{array}$ & $\begin{array}{l}\text { Integración individual del extranjero. Defensa de la iden- } \\
\text { tidad y de la lengua española en Cataluña. }\end{array}$ \\
\hline
\end{tabular}

Fuente: Elaboración propia 
Los disensos en ocasiones pueden ser fuego cruzado más entre regiones, o bien entre las Comunidades Autónomas y el Gobierno del Estado. Aquí entra en juego la dinámica de desgaste político entre gobierno y oposición, y los intereses electorales de los distintos partidos políticos. Más que en el discurso, con su riqueza y con la excepcionalidad catalana por su elaboración verbal, quizás las diferencias en el ámbito autonómico se puedan ubicar en la gestión e implementación de políticas públicas en este ámbito específico. Porque allí donde no hay reivindicación cultural propia es complejo que se plantee un debate más allá del discurso de la desigualdad social. Eso si, el discurso centralista siempre ha tenido problemas en imaginarse como una comunidad plural y diversa en lo cultural, lingüístico e identitario y en cómo integrar en clave interna las demandas descentralizadoras y, desde luego, la inmigración y el discurso sobre su acomodación simplemente nos han iluminado este hándicap siempre inconcluso en el debate entorno al estado español y las diversas nacionalidades históricas. Acaso, ¿podríamos defender la interculturalidad para la integraci-

ón de los extranjeros, a la par que recetar la asimilación para los díscolos de las nacionalidades históricas?

\section{Bibliografía}

BOSWELl, Christina; GEDDES, Andrew; SCHOLTEN, Peter. The role of narratives in Migration Policy-Making: A Research Framework. British Journal of Politics and international Relations. V. 13, n. 1, pp. 1-11. 2011.

BOSWELL, Christina. Theoring migration policy: Is there a thrid way? International Migration Review. V. 41. n.1, pp. 75-100. 2007.

CAMÓS VICTORIA, Ignasi. La participación de los gobiernos locales en las políticas de inmigración: las competencias municipales en materia de inmigración. In: AA.VV.: Inmigración y gobierno local: experiencias y retos. Barcelona: Fundación CIDOB, 2007. p. 25-38.

CZAIKA, Mathias; DE HAAS, Hein (2013): The effectiveness of Immigration Policies. Population and Development Review. V.39, n. 3, p. 487-508. 2013.

DOMINGO, Andreu. "Català és..." El discurs sobre immigració i identitat nacio- 
nal durant el franquisme: Francecs Candel y Jordi Pujol. Treballs de la Societat Catalana de Geografia. n. 75, p. 9-32. 2013.

FAVELL, Adrian. Philosophies of Integration. Immigration and the idea of citizenship in France and Britain. Hampshire: Palgrave, 1998

FREEMAN, Gary P. National models, policy types, and the Politics of Immigration in Liberal Democracies. West European Politics. V. 29, n. 2, p. 227-247. 2006.

HERNÁNDEZ-CARR, Aitor. El salto a la nueva extrema derecha: una aproximación a los votantes de Plataforma per Catalunya. Revista Política y Sociedad. V. 50, n. 2, p. 601-627. 2013.

HERNÁNDEZ-CARR, Aitor. El largo ciclo electoral de Plataforma per Catalunya: del ámbito local a la implantación nacional (2003-2011). Working Papers no. 300, Institut de Ciències Polítiques i Socials (ICPS): Barcelona, 2011. Link: http://ddd.uab.cat/pub/worpap/2011/hdl_2072_172919/ICPS300.pdf [Último acceso: 27 de Febrero de 2015].

MARTÍN-PÉREZ, Alberto; MORENO-FUENTES, Francisco Javier. Migration and Citizenship Law in Spain: Path Dependency and Policy Change in a Recent Country of Immigration. International Migration Review, v. 46, n. 3, p. 625-655. 2012.

MARTINIELLO, Marco. Salir de los guetos culturales. Barcelona: Editorial Bellaterra, 1998.

MIRET I SERRA, Angel. La gestión de la división de competencias en materia de inmigración. In: ZAPATA BARRERO, Ricard (coord.). Políticas y gobernabilidad de la inmigración en España. Madrid: Ariel, 2009. p. 51-72.

MONTILLA MARTOS, José Antonio, RODRÍGUEZ CANDELA, José Luís. Las normas generales del Estado en 2009-2910. In: AJA FERNÁNDEZ, Eliseo; ARANGO VILA-BELDA, Joaquín (coord.). Inmigración y crisis: entre la continuidad y el cambio. Barcelona: Fundació CIDOB, 2011. p. 324-349.

NUSSBAUM, Martha C. La nueva intolerancia religiosa. Cómo superar la política del miedo en una época de inseguridad. Barcelona: Paidós, 2013.

RAMÍREZ, Ángeles. La trampa del velo. El debate sobre el uso del pañuelo musulmán. Madrid: Los libros de la catarata, 2011.

SCUZZARELLO, Sarah. Policy actor's narrative constructions of migrants' integration in Malmö and Bologna. Ethnic and Racial Studies, v. 38, n. 1, p. 57-74. 2013.

ZAPATA-BARRERO, Ricard. Diversity Management in Spain: New dimensions, new challenges. Manchester: Manchester University Press, 2013.

Recepção dos artigos: 30/06/2015

Data de aprovação 30/07/2015 
